\title{
Avoiding Diagnostic Lens Fogging During the COVID-19 Era
}

This article was published in the following Dove Press journal: Clinical Ophthalmology

\section{David Pérez González (iD) Anat Loewenstein' Dan D Gaton ${ }^{2}$ \\ 'Department of Ophthalmology, Tel Aviv Sourasky Medical Center, Sackler Faculty of Medicine, Tel Aviv, Israel; ${ }^{2}$ Department of Ophthalmology, Rabin Medical Center, Sackler Faculty of Medicine, Tel Aviv, Israel}

\section{Video abstract}

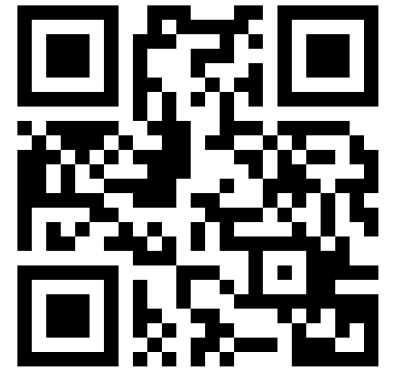

Point your SmartPhone at the code above. If you have a $Q R$ code reader the video abstract will appear. Or use: https://youtu.be/6ixfruTlcqs
Correspondence: David Pérez González Department of Ophthalmology,

Tel Aviv Sourasky Medical Center, Sackler Faculty of Medicine, Weizmann Street \#6,

Tel Aviv 6423906, Israel

Tel +972 -58-767-847।

Email davidperezgonzalez90@gmail.com
Abstract: Since the advent of COVID-19, the patient's use of a face mask hampers our visibility because there is a marked fogging in our view produced by the warm breath that escapes from the top of the patient's mask and lands on the cooler surface of the lens. This panorama is sometimes so frustrating that we have been forced to ask our patients to remove their facemasks while examined, increasing the risk of being infected. We consider it essential to share this small pearl technique that we can apply in order to avoid fogging during the examination; it is easy, and most importantly, without putting at risk the patient or doctor's health. In our opinion, this is the first material to propose this technique.

Keywords: technique, diagnosis, ophthalmology, enhancement, clarity

\section{Commentary}

This year humanity has to face an unprecedented situation; since the advent of the COVID-19 pandemic, life as we previously knew it had been drastically turned over. In medical practice, the interaction between patients and doctors has been physically and emotionally challenged due to the new demand of wearing personal protective equipment (PPE) by the medical staff and the patient.

We all know by now that the virus can be spread by coughing, sneezing, breathing, as well as talking, sending multiple micro-particles in the air. The concern of a direct ocular transmission mechanism has emerged, although the specific means involved in this process have not been fully understood. Like all viruses, SARS-CoV-2 needs an affinity tool that allows cellular interaction and gene cell incorporation. The angiotensin-converting-enzyme 2 receptor (ACE2) and its cell transmembrane protease, serine 2 (TMPRSS2), currently depict the primary roles aiming this process. ${ }^{1}$ ACE2 and TMPRSS2 are highly expressed and recognized in different ocular structures, including the conjunctiva, cornea, trabecular meshwork, and even the retina. ${ }^{2,3}$ Theoretically, this will allow the virus to adhere, prevail, and replicate, overstepping the ocular surface and disseminate systemically into the body. ${ }^{2}$ The dispersion of the virus in the tear film has also been considered another critical route for possible transmission, and albeit there is good evidence that shows the presence of SARS-CoV -2 in tears, it has been demonstrated that the virus can not be detected in the conjunctival sac without prior signs of conjunctivitis. ${ }^{4}$ However, in patients who initially displayed these signs, continuous presence and active replication of the pathogen have been observed, even in entirely asymptomatic subjects. ${ }^{2,4}$ Therefore, it becomes emphatic to properly use PPE's armamentarium to avoid contact with contaminated droplets and bioaerosol emitted by patients who can reach our face and 
eyes. Findings continued to support the idea that masks, in general, are associated with a considerable reduction in risk of infection from SARS-CoV-2, and this reduction markedly increases with an appropriate distance of at least 1 meter. $^{5}$ As ophthalmologists, we can hardly opt for the benefit of distance in our daily practice, and we are at high risk since getting really close to our patients during slit-lamp examinations.

Currently, recommendations are vague regarding how to approach different therapeutic and medical work-related situations. In this sense, the medical staff is often left behind and is forced to make decisions and face these responsibilities independently. ${ }^{6}$ The American Academy of Ophthalmology (AAO), after the first peek of the pandemic, detailed recommendations on dealing with standard practice in the COVID-19 era, even then inviting ophthalmologists to "make individual decisions" regarding the use of PPE. ${ }^{7}$ Nevertheless, national and international ophthalmological guidelines and recommendations, as well as common sense, advocate using protective shields on the slit-lamp instruments and wearing a facemask during interaction with patients by both physician and patient. ${ }^{5,8,9}$

Although being mandatory and needed, the patient's use of a facemask hampers the visibility of the retina. While we are examining the patient with our indirect non-contact or contact direct lens, there is a marked fogging in our view produced by the warm breath that escapes from the top of the patient's mask and lands on the cooler surface of the diagnostic lens (Figure 1). At some point, this limitation may trigger the inappropriate use of protection, removing the patient's facemask during the examination with an increased risk of contagion.

In the light of these events we propose a simple technique that can be applied to each patient wearing a facemask (Figure 1):

1. The patient rests the head and chin on the slit-lamp instrument, properly wearing the facemask, covering the mouth and nose.

2. A non-contact indirect lens (78 or $90 \mathrm{D})$, or a contact (Goldman 3 mirror lens) is held at its proper position.

3. While holding the lens with the first and second fingers, we create a gentle but proper pressure over the upper edge of the mask against the patient's cheekbone with our annular and pinky finger. In this manner, we avoid that warm breath escapes from the top of our patient's mask, consequently avoiding fogging over the lens.

4. Also note that our third finger is still available in case we need to elevate the patient's eyelid gaining full eye exposure for fundus and anterior chamber angle examination, thus improving visualization.

\section{Conclusion}

Although there is plenty of evidence and guidelines with continuous exponential growth, they should be considered an adjacent tool that still needs a personal context application concerning each situation in our daily practice. This technique is a useful adjuvant through this island of individuality regarding this specifical situation. On the other
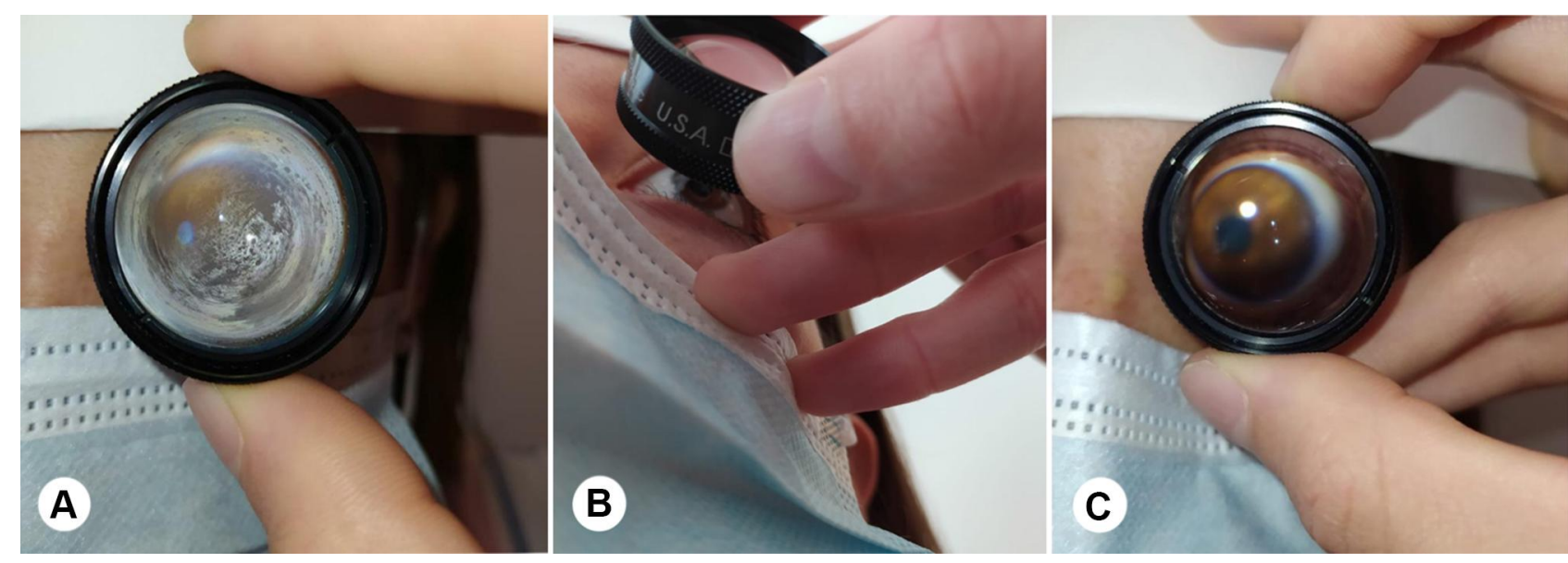

Figure I Avoiding lens fogging during examination. (A) While using a non-contact indirect lens for fundoscopic examination, warm breath reaches the lens's cold surface with consequent fogging. (B) we hold the lens between the first and second finger, with the middle and pinky finger we create gentle but proper pressure in the superior margin of the mask, against the patient's cheekbone $(\mathbf{C})$ as we follow this prior steps while examining the patient, we prevent that warm breath escapes from the top of patient's mask, consequently avoiding fogging. 
hand, it is not out of the equation to note that, despite touching the patient's mask's anterior surface may expose to more significant contact with eye secretions, acquiring coronavirus by this path has not been fully demonstrated. ${ }^{10}$ We also consider that, given the current regulations of constant handwashing after each examination and adding gloves will significantly reduce this exposure, and in no way will this be riskier than removing the patient's mask, as usually happens.

Adaptation and creativity have been part of human evolution, and we hope that sharing this little pearl with the ophthalmological community, however simple it may seem, will aid in patient management during this difficult time.

\section{Disclosure}

Anat Loewenstein reports grants from Sensor, Allergan, and Bayer and is a consultant for Allergan, Bayer, Novartis, Notal - Vision, Syneos health, Beyeonics, Roche, KHB, outside the submitted work. The authors report no other potential conflicts of interest for this work.

\section{References}

1. Shang J, Wan Y, Luo C, et al. Cell entry mechanisms of SARS-CoV-2. Proc Natl Acad Sci. 2020;117(21):11727-11734. doi:10.1073/ pnas. 2003138117
2. Napoli PE, Nioi M, D'Aloja E, Fossarello M. The ocular surface and the coronavirus disease 2019: does a dual 'Ocular route' exist? J Clin Med. 2020;9(5):1269. doi:10.3390/jcm9051269

3. Holappa M, Vapaatalo $H$, Vaajanen A. Many faces of renin-angiotensin system - focus on eye. Open Ophthalmol J. 2017;11(1):122-142. doi:10.2174/1874364101711010122

4. Xia J, Tong J, Liu M, Shen Y, Guo D. Evaluation of coronavirus in tears and conjunctival secretions of patients with SARS-CoV-2 infection. J Med Virol. 2020;92(6):589-594. doi:10.1002/jmv.25725

5. Chu DK, Akl EA, Duda S, et al. Physical distancing, face masks, and eye protection to prevent person-to-person transmission of SARS-CoV-2 and COVID-19: a systematic review and meta-analysis. Lancet. 2020;395(10242):1973-1987. doi:10.1016/ S0140-6736(20)31142-9

6. Napoli PE, Nioi M, D'Aloja E, Fossarello M. Safety recommendations and medical liability in ocular surgery during the COVID-19 pandemic: an unsolved dilemma. J Clin Med. 2020;9(5):1403. doi: $10.3390 / \mathrm{jcm} 9051403$

7. Ophthalmology AA of. Returning to Ophthalmology Practice; 2020. Available from: https://www.aao.org/about/governance/academy-blog /post/returning-to-ophthalmology-practice. Accessed November 18, 2020.

8. CDC. WHO. Important coronavirus updates for ophthalmologists. American Academy of Ophthalmology; 2020. Available from: https://www.aao.org/headline/alert-important-coronavirus-context. Accessed December 14, 2020.

9. Ong SC, Yap JX, Tay TYF, Mo Y, Loon SC, Koh V. Considerations in the use of slit lamp shields to reduce the risk of respiratory virus transmission in coronavirus disease 2019. Curr Opin Ophthalmol. 2020;31(5):374-379. doi:10.1097/ICU.0000000000000690

10. Seah IYJ, Anderson DE, Kang AEZ, et al. Assessing viral shedding and infectivity of tears in coronavirus disease 2019 (COVID-19) patients. Ophthalmology. 2020;127(7):977-979. doi:10.1016/j. ophtha.2020.03.026
Clinical Ophthalmology

\section{Publish your work in this journal}

Clinical Ophthalmology is an international, peer-reviewed journal covering all subspecialties within ophthalmology. Key topics include: Optometry; Visual science; Pharmacology and drug therapy in eye diseases; Basic Sciences; Primary and Secondary eye care; Patient Safety and Quality of Care Improvements. This journal is indexed on PubMed

\section{Dovepress}

Central and CAS, and is the official journal of The Society of Clinical Ophthalmology (SCO). The manuscript management system is completely online and includes a very quick and fair peer-review system, which is all easy to use. Visit http://www.dovepress.com/ testimonials.php to read real quotes from published authors. 